\title{
PLAGAS ENTOMOLÓGICAS Y OTROS ARTRÓPODOS EN EL CULTIVO DE LA PIÑA (Ananas comosus var. comosus (L.) Merr., Coppens \& Leal) EN CHANCHAMAYO Y SATIPO, DEPARTAMENTO DE JUNÍN, PERÚ
}

\section{INSECT PESTS AND OTHER PINEAPPLE (Ananas comosus var. comosus (L.) Merr., Coppens \& Leal) CROP ARTHROPODS IN CHANCHAMAYO AND SATIPO, DEPARTMENT OF JUNIN, PERU}

\author{
Germán Arellano ${ }^{1}$, Clorinda Vergara ${ }^{2}$ y Segundo Bello ${ }^{3}$
}

\begin{abstract}
Resumen
El presente estudio tiene como objetivo determinar las plagas entomológicas en el cultivo de la piña en la selva del Departamento de Junín, Perú. Se considera como base las evaluaciones realizadas entre los años 1983 a 1987, actualizando las determinaciones de las especies, e incorporando información reciente. La evaluación se basó en colectas periódicas mensuales de insectos en las plantaciones de piña y en la vegetación herbácea del cultivo, registrándose la abundancia, importancia, daños, hospedadores alternos y enemigos naturales durante estos años. Los especímenes colectados en campo y recuperados en el laboratorio, fueron remitidos al Museo de Entomología "Klaus Raven Büller" de la Universidad Nacional Agraria La Molina, para su montaje y determinación. En los resultados de este trabajo se confirma que la "mosca de la piña" Melanoloma viatrix Hendel, que ataca a los frutos, representa el problema entomológico más grave. Los ácaros que viven en las cavidades florales e insectos asociados a la inflorescencia, podrían ser vectores y diseminadores de Fusarium moniliforme Sheldon y Penicillum funiculosum Thom que producen las "manchas negras en los frutos". En este trabajo se consideraron como problemas potenciales a la "broca de la piña" Strymon megarus (Goardt) y la "cochinilla de la piña" Dysmicoccus brevipes (Cockerell).

Palabras clave: Ananas comosus, Melanoloma viatrix, Strymon megarus, Dysmicoccus brevipes.
\end{abstract}

\begin{abstract}
This study was focused in the determination of entomological pests in pineapple plantations in the rainforests of the Department of Junín, Peru. Based on assessments carried out from 1983 to1987, species determinations were updated and recent information was incorporated. The evaluation was based on regular monthly insects collects in pineapple plantations and in the herbaceous vegetation in the plantations, recording abundance, importance, damage, alternate hosts and natural enemies over these years. The specimens collected in the field and recovered in the laboratory were sent to the "Klaus Raven Büller" Entomology Museum of the Universidad Nacional Agraria, La Molina, for mounting and identification. The results of this work confirmed that the "pineapple fly" Melanoloma viatrix Hendel, which attacks the fruit, was the most serious entomological problem. Mites that live in floral cavities and insects associated with the inflorescence could be vectors and disseminators of Fusarium moniliforme and Penicillium funiculosum that cause "black spots on the fruit." In this paper the "pineapple fruit borer" Strymon megarus (Goardt) and the "pineapple mealybug" Dysmicoccus brevipes (Cockerell) were considered as potential problems
\end{abstract}

Key words: Ananas comosus, Melanoloma viatrix, Strymon megarus, Dysmicoccus brevipes

\section{Introducción.}

El cultivo de la piña Ananas comosus var. comosus (L.) Merr., Coppens \& Leal (Coppens d'Eeckenbrugge \& Leal, 2003) en Chanchamayo y Satipo (Departamento de Junín, Perú), ocupó el tercer lugar en importancia nacional hasta 1983. En 1989, aproximadamente 1913 ha fueron destinadas a este frutal en la "Selva Central”, con una producción de 16 TM/ha, esta producción fue considerada baja debido a técnicas precarias en el manejo del cultivo, bajas densidades de plantación, sin uso de fertilizantes, en terrenos pobres y de topografía abrupta. Presentó como principales problemas las "manchas" en la pulpa de los frutos, que disminuyeron su calidad para la 
industria y como fruta fresca, también existió la "gomosis", frutos con desarrollo anormal, deficiencias de elementos como potasio, magnesio y boro (Bello, 1989) y hasta 1993 la Selva Central se aproximó a 2000 ha en el cultivo de la piña casi el $100 \%$ de ‘Samba de Chanchamayo’ (Julca \& Bello, 1994). Pero a partir del año 2000 las plantaciones de piña aumentaron considerablemente debido principalmente a la destrucción de las plantaciones del cítrico (Tangelo) por efecto del hongo Alternaria alternata (Fries) Keissler, inicialmente los cítricos fueron reemplazados por la piña 'Azúcar' nombrada como "Hawaina" y últimamente se ha incrementado fuertemente el cultivo de la piña MD-2 por la calidad de la fruta. En el Perú se estima alrededor de 12000 ha sembradas, siendo la zona más importante la "Selva Central” (Bello et al., 2008). Sin embargo, de acuerdo con la Oficina de Estudios Económicos y Estadísticos del Ministerio de Agricultura (MINAGRI), los productos agrícolas que experimentaron aumentos a nivel nacional en los primeros siete meses del año 2013 fueron mango, alfalfa, caña de azúcar, maíz amiláceo, arroz cáscara, choclo, palta, espárrago y piña, no existiendo mayor información disponible sobre el cultivo tratado en este trabajo (MINAGRI, 2013). Debido a la importancia que está adquiriendo el cultivo de la piña en los últimos años y los escasos trabajos publicados relacionados con las plagas entomológicas, por lo que este trabajo tiene como objetivo determinar las plagas entomológicas en el cultivo de la piña. En base a estudios realizados a partir de 1983 con los resultados preliminares de un proyecto de investigación sobre evaluación de plagas de la piña en la zona, complementado con trabajos recientes, y actualizando las determinaciones de las especies.

En la zona, de Chanchamayo y Satipo la mayoría de los campos de piña desde la década 1980 fueron de pequeños y medianos agricultores, ubicados entre los 800 y 1500 msnm, en ambos márgenes de los ríos Chanchamayo y Perené, desde la Merced a Pichanaki (Bello, 1989). Muchas plantaciones están sobre pendientes fuertes en terrenos sueltos y la plantación se mantenía en producción con un promedio de siete años de edad (FAO, 1983). Las principales áreas de cultivo fueron Chincana, Quimiri, Villa Progreso, Río Seco, Metraro y Toterani. Entre los cultivares destacaron: la 'Norteña' o 'Cabezona', ‘Azúcar' o 'Blanca', 'Roja Trujillana', 'Guayaquil’ y 'Rosada', hasta entonces (Bello, 1989).

Entre las plagas más importantes, Faura (1967), cita a la "queresa harinosa" Pseudococcus maritimus Ehrhron como única plaga para Chanchamayo. Combe \& Zapata (1964) registraron como plagas en este cultivo para la Amazonia Peruana a la "queresa hemisférica" Saissetia coffeae (Walker) (Hom., Coccidae) y el "perforador de los frutos" Metamasius hemipterus L. (Col., Curculionidae).
Py et al. (1984) señalan que las "manchas de los frutos" fueron causadas por los hongos Fusarium sp. y Penicillum sp., cuyos agentes vectores son los ácaros de la inflorescencia, además mencionan a la abeja Trigona spinipes (Fabricius), la "broca de la piña" Thecla basilides (Geyer) (Lep., Lycaenidae) y la "cochinilla de la piña" Dysmicoccus brevipes (Cockerell) (Hom., Pseudococcidae), que son especies de amplia distribución en América del Sur. Julca \& Bello (1994) citan que a nivel latinoamericano una de las plagas más importantes es Techla basilides, estimándose para México pérdidas similares a 10 millones de pesos en 1968. Julca \& Bello (1994) mencionan que Arellano G. registró por primera vez esta especie en Satipo en al año 1988 en 'Cayena Lisa'. En este mismo trabajo encontraron el mayor daño de este insecto en la cosecha entre julio y septiembre, que fue el $60 \%$ mayor que en abril citando pérdidas económicas en el orden de 2500 dólares/ha para ese año, llegando a considerar a esta especie como plaga clave. También estudiaron su biología y recomendaron investigaciones más detalladas incluyendo las especies controladoras biológicas.

La "mosca de los frutos de la piña" Melanoloma canopilosum (Hendel) fue citada causando daño en 'Samba' por Figueroa et al. (1970). Muchos años después, Bello et al. (1997) asociaron a la mosca con un tipo de mancha que denominaron macha con galerías; posteriormente, Bello et al. (2008) evaluaron en Chanchamayo el efecto de la protección mecánica de la inflorescencia y el uso de trampas caseras en el control de la "mancha de los frutos" de la piña causados por patógenos cuyos vectores son los insectos, que interactúan con la inflorescencia logrando resultados exitosos en el control de dicha patología.

\section{Materiales y métodos.}

El trabajo de campo que ha servido como referencia se realizó en dos fundos del Instituto Regional de Desarrollo Selva de la Universidad Nacional Agraria La Molina (Perú): a) El fundo Génova con 577 ha, en el valle de Chanchamayo en la margen izquierda del río, cerca de San Ramón entre los 940 msnm y $1200 \mathrm{msnm}$ sede del equipo de trabajo y el lugar del laboratorio. b) El fundo Santa Teresa con 300 ha, situado en el valle de Río Negro a $9.5 \mathrm{~km}$ de la ciudad de Satipo sobre la Carretera Marginal, a $850 \mathrm{msnm}$ donde se encontraban los ensayos y plantaciones de distintos tipos de piña. El estudio de observación experimental se realizó desde octubre de 1984 hasta agosto de 1987. En estos lugares, además, se efectuaron algunas visitas a otros fundos a lo largo de la Carretera Marginal para recoger información sobre la problemática de la piña también en la zona de Chanchamayo (Figura 1). El presente artículo recoge información de trabajos 


\section{AREA CHANCHAMAYO - SATIPO}

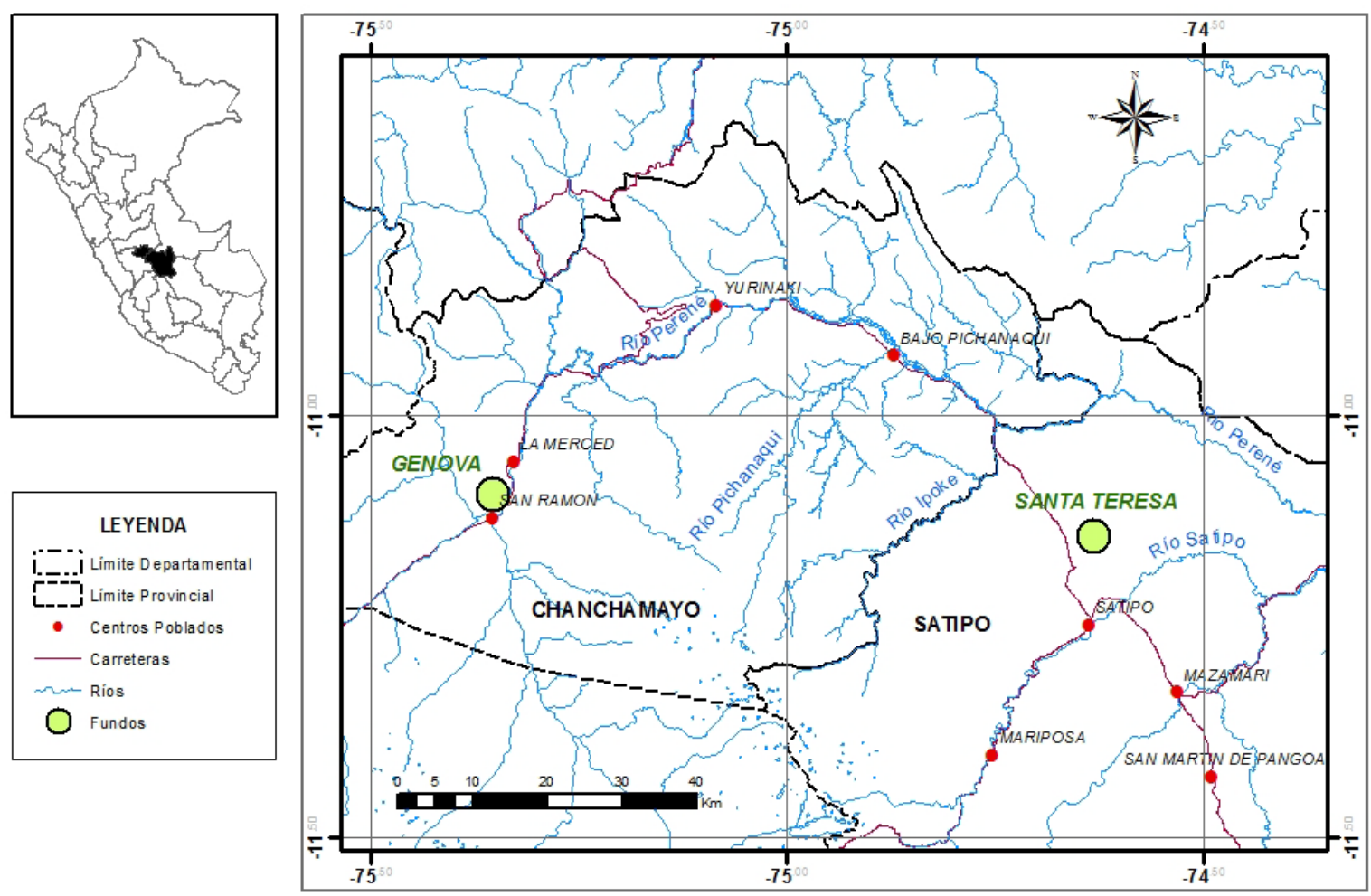

Figura 1. Localización del área de estudio y su zona de influencia en la Carretera Marginal de la Selva entre las ciudades de San Ramón y Satipo en el Departamento de Junín y la ubicación de los fundos Génova en Provincia de Chanchamayo y Santa Teresa en Provincia de Satipo (Perú). Fuente: Elaboración propia.

posteriores en la zona, realizados por otros autores, a fin de discutir y actualizar los resultados obtenidos en estas fechas.

Características de la zona de influencia

La zona de influencia se localiza entre los 450 msnm y los 2000 msnm encontrándose, por esta razón variaciones en el régimen climático sobre los lugares donde se desarrollan los cultivos. Los datos usados para los análisis climatológicos en este trabajo, referidos a la parte baja de San Ramón (Chanchamayo), fueron proporcionados por la estación meteorológica del Centro Internacional de la Papa. A unos 850 msnm. En general el clima de la zona se caracteriza por una estación seca no mayor de tres meses (Bello, 1989) y el resto del año con precipitaciones que permiten el cultivo de plantas perennes. La temperatura máxima promedio anual fue de 30o C. La mínima promedio anual fue de 17.7o C. Las temperaturas más altas se registraron en octubre y noviembre y las más bajas en el mes de julio. En general durante el año las temperaturas tanto máximas como mínimas, no tuvieron variaciones extremas, por su parte, la precipitación fue el factor físico ambiental más importante en los ciclos biológicos y en el comportamiento de los insectos.
La precipitación total anual promedio entre 1983 y 1987 fue de $1955.01 \mathrm{~mm}$, distribuida de forma irregular en el transcurso del año. Se observaron tres épocas definidas de caída de lluvias: 1) época de mayor precipitación, que fue de diciembre hasta abril, en la cual se registraron precipitaciones superiores a los $200 \mathrm{~mm} / \mathrm{mes}$, el $60 \%$ del total de la precipitación cayó en esta época. 2) época seca, de mayo a agosto, en la cual las precipitaciones promedio fueron menores de $100 \mathrm{~mm} / \mathrm{mes}$, el $18 \%$ del total de las precipitaciones. 3) época del inicio de la precipitación, de setiembre a noviembre, en la cual las precipitaciones promedio estuvieron en $140 \mathrm{~mm} / \mathrm{mes}$, el $22 \%$ del total de las precipitaciones se produjo en esta época. Este período coincidió con el inicio de las labores de las campañas agrícolas. Este régimen de lluvias permitió el cultivo de frutales y otras plantas perennes sin riego. Es de esperar que las condiciones ambientales que existieron en este estudio habrán cambiado en la actualidad.

Áreas de muestreo

En el cultivo de la piña las evaluaciones se realizaron en lotes experimentales y en el "Banco de Germoplasma de la Piña” del fundo Santa Teresa desde enero de 1985, y durante el tiempo que se realizó este estudio, también se realizaron colectas en 
otros lugares de producción de piña de la zona. Las áreas de muestreo fueron las siguientes:

a) Las parcelas experimentales que tenían 4 densidades de siembra y constituyeron ensayos de introducción 'Cayena Lisa', los distanciamiento usados fueron $0.4 \times 0.5 \times 1.7 \mathrm{~m}, 0.35 \times 0.5 \times 1.9 \mathrm{~m}$, $0.40 \times 0.5 \times 1.6 \mathrm{~m}, 0.4 \times 0.6 \times 1 \mathrm{~m}$, se iniciaron con menos de 1 ha, posteriormente se incrementó con la propagación de hijuelos hasta 3 ha.

b) El banco de germoplasma que reunió 12 cultivares de piña recolectados en la zona, en un área aproximada de 0.5 ha. Se trabajó en los siguientes: 'Cayena Lisa', 'Samba de Chanchamayo', 'Rosada', 'Lagarto’, ‘Azúcar’, 'Roja española’ y ‘Manzana’.

c) Respecto de otras áreas de colección, en Chanchamayo y Satipo las plantaciones de piña de los agricultores fueron conducidas en manejo semiintensivo, con bajas densidades de siembra. La distancia entre las plantas era en la mayoría de los casos de $1 \mathrm{~m}$ x $1 \mathrm{~m}$ (menos de 20000 plantas/ha). Las plantaciones se mantenían habitualmente de 5 a 6 años, posteriormente eran abandonadas, o se dejaban en descanso por uno o varios años. No se realizaban prácticas de abonamiento, ni labores fitosanitarias (Bello, 1989). En estas áreas, con plantaciones abandonadas donde las especies fitófagas incrementaron sus poblaciones, se realizaron algunas recolectas en otros lugares como en "Quimiri Sur" el 30 de abril de 1985, “Quimiri Sur y Centro” el 13 de noviembre de 1985 (Chanchamayo) y "Centro Toterani” el 12 julio de 1985 (Valle del Perené Satipo), con el fin de recuperar parasitoides de plagas. Asimismo en el centro de acopio que existió de la industria que procesaba la fruta para elaborar conservas (INDALSA) y observación de la fruta que era trasportada en camiones por la Carretera Marginal en julio de 1985 y en julio de 1987, para determinar el grado de infestación de la "mancha de los frutos". Otro lugar en el que se hicieron recolectas fue "Metraro" en el valle del Perené (Satipo) en noviembre de 1985; este cultivo tenía un buen manejo agronómico y la producción era apreciada en la industria.

\section{Muestreo de insectos}

El muestreo se basó en recolecciones periódicas mensuales de insectos en las plantaciones de piña y en la vegetación herbácea del cultivo, registrándose la abundancia, importancia, daños, hospedadores alternos y enemigos naturales asociados durante estos años. Las muestras fueron trasladadas del campo al laboratorio en el fundo Génova (Chanchamayo), en el cual se realizaron las crianzas y recuperación de adultos y parasitoides, observaciones de la biología y embalaje del material entomológico. Los especímenes de la recolecta del campo y recuperados en el laboratorio fueron remitidos al Museo de Entomología "Klaus Raven Büller" de la Universidad Nacional Agraria La Molina para su montaje y determinación.
El método de recolección consistió en la captura de insectos adultos, inmaduros y puestas, mediante aspiradores tradicionales de succión, redes entomológicas aéreas y de golpe, pinzas, serrucho de podar, tijeras, etc., sobre cualquiera de las partes de las plantas cultivadas. En la hierba la colección se hizo básicamente con red de golpe, realizando batidas de ida y vuelta sobre la maleza. Las plantas que se evaluaron fueron escogidas al azar a lo largo de una línea en diagonal que cruzaba el campo, de esta forma se realizó un muestreo aleatorio simple. Las colectas duraron de 4 a 6 horas, durante el día en horas de luz y de mayor temperatura, entre las 9 y 15 horas, interdiarias y 1 semana al mes. En la maleza la colecta se realizó durante 1 hora siguiendo la misma ruta una vez concluidas las observaciones de las plantas cultivadas.

Estas evaluaciones permitieron identificar poblaciones de insectos que podrían convertirse en problemas, y a estas especies se les daba un tratamiento especial según su comportamiento que será descrito posteriormente. Con este método básico se registraron las plagas más importantes durante estos años, que fueron objeto de especial atención con muestreos diseñados según los hábitos de las especies.

Evaluación de plagas

Sobre estas plantaciones se hicieron las evaluaciones mediante el método de muestreo básico descrito anteriormente. En la piña 'Cayena Lisa', el daño se determinó mediante el porcentaje de frutos afectados por la "broca de la piña" y también, la "mosca de la piña". En todos los casos para el estudio de la "broca de la piña”, la "mosca de la piña” y ácaros, se contaban todas las inflorescencias, los frutos verdes, pintones, maduros y en pudrición de los lotes de Santa Teresa, el daño se expresó en porcentajes. También se tomaron como muestras 10 inflorescencias, 10 frutos verdes, 10 frutos pintones, 10 frutos maduros y 10 frutos en estado de pudrición, este último en otras plantaciones abandonadas, para las observaciones en el laboratorio.

Los métodos de observación en el laboratorio para especies de importancia que afectaron el cultivo fueron los siguientes:

a) La "mosca de la piña" Melanoloma viatrix Hendel. Esta especie ha sido citada como Melanoloma canopilosum (Hendel) de acuerdo a una primera determinación, sin embargo posteriormente los autores han hecho la consulta al Dr. Cheslavo Korytkowski especialista Tephritoidea de la Universidad de Panamá, quien concluye que se trata de $M$. viatrix siendo la misma especie que se cita para otros países de la Región Neotropical. Fue observada en el laboratorio en los frutos procedentes de las recolectas de "Santa Teresa" y otros lugares señalados anteriormente durante el año 1985; y también en los años 1986 y 1987 en los que se recuperaron los adultos y la posibilidad de obtener sus parasitoides. 
Se desarrolló un método de crianza con los mismos frutos. Estos fueron puestos en frascos de vidrio de 10 l de capacidad, con aserrín en la base para absorber el exceso de humedad que causaban las exudaciones fermentadas de los frutos con ataque de mosca, los frascos fueron cerrados con mangas de tela de organza donde los individuos que venían del campo completaron su desarrollo.

El 16 de julio de 1987, ingresaron al laboratorio 18 frutos (con un peso total de $33 \mathrm{Kg}$.); en 15 de ellos (10 verdes y 5 pintones), con el fin de detectar si los frutos eran atacados en cada estado de maduración, se cortaron en finas rodajas cada uno de ellos y se hicieron observaciones detalladas, cuantificándose las larvas de la mosca, el número de grupos de larvas de tamaño homogéneo, el daño que causaban en los frutos y la reacción de los tejidos con exudaciones gomosas (manchas). Se continuó con la crianza de 969 larvas de último estadío, estas larvas fueron puestas en 4 frascos de 10 l y 1/10 de su capacidad con arena previamente esterilizada para que se formaran las pupas.

En los frutos provenientes de esta y otras recolectas con la misma técnica de disección, también se pudo observar y contar manchas de diferente coloración en la pulpa del fruto. Se tomaron muestras y se enviaron al Departamento de Fitopatología de la Universidad Nacional Agraria La Molina y el Institut de Recherche sur les Fruits et Agrumes (IRFA) de Francia, para la determinación de los patógenos. También se tomaron muestras de los ácaros de las inflorescencias y frutos de piña de los distintos lugares de colección y se enviaron al Museo de Entomología de la Universidad Nacional Agraria La Molina.

El daño de $M$. viatrix fue primario, las larvas de estas moscas barrenan la infrutescencia, cuando son pequeñas no hay síntomas externos de la infestación; a medida que crecen producen la maduración prematura con fermentación de las infrutescencias, algunas veces acompañada con gomosis. La fruta atacada no tiene valor para la industria y es menos apreciada en el consumo interno. $M$. viatrix atacó todas las variedades de piña observadas en Satipo.

b) La "broca de la piña". Strymon megarus (Goardt). Esta especie ha sido citada para el Perú como Thecla basilides (Geyer); sin embargo, Beutelpacher (1972) y Frank \& Louibos (2008) citados por Schmid et al. (2010), establecen que $S$. megarus es sinónimo de $T$. basilides y de $T$. basalides (W.F. Kirby); las larvas se alimentan de Ananas comosus (piña comercial) y otras bromeliáceas donde es considerada especie plaga. Robbins (2010) y Robbins et al., (2012) manifiestan que existe una confusión entre las diferentes especies de Strymon (Hewitson), S. megarus, S. lucena (Hewitson) $S$. oreala (Hewitson), S. serapio (Godman \& Salvin), $S$. azuba (Hewitson), y S. gabatha (Hewitson); en la mayoría de los casos, las orugas comen las flores y frutas de bromeliáceas, pero las larvas de $S$. megarus y/o $S$. ziba también pueden perforar las hojas cuando las flores y las frutas no están disponibles, y son especialmente destructivas en los cultivos de piña; sin embargo existen caracteres distintivos entre las especies. Callaghan et al. (2004) establecieron la sinonimia, $S$. megarus es sinónimo de $T$. basilides en Brasil, T. basalides y T. tigonia (Schaus) en Perú. $S$. amphyporphyra K. Jonson, Eisele \& MacPherson en Argentina, S. rotundum Austin \& Johson en Brasil y S. gallardi Faynel \& K. Johnson en Guyana Francesa.

En 10 muestras de inflorescencias y cinco frutos tiernos de piña procedentes de Santa Teresa el 27 de julio de 1986, se realizaron las observaciones de la biología de la "broca de la piña"; los pedúnculos florales o los frutos tiernos fueron puestos cada uno en un pequeño frasco con agua, que fue repuesta constantemente, y estos a su vez se colocaron en otro frasco de $10 \mathrm{l}$ con aserrín en el fondo, de esta manera se mantenía por más de un mes las inflorescencias que inicialmente contenía los huevos de esta especie. Este método de conservación de las inflorescencias y frutos tiernos permitió hacer observaciones biológicas y recuperar parasitoides.

En junio 2015 ingresó al Museo de Entomología “Klaus Raven Büller” especímenes procedentes de una crianza en gabinete del fundo La Bretaña en San Ramón Chanchamayo, en la piña 'Golden' que permitió confirmar la presencia de la especie hasta la fecha.

c) "Cochinillas harinosas". En las muestras mencionadas anteriormente y en las de otras recolectas como Metraro y Quimiri, también se encontraron infestaciones sobre la infrutescencia por Dysmicoccus brevipes (Cockerell), con este mismo método de crianza se logró recuperar parasitoides identificando también las "cochinillas harinosas" parasitadas. El control biológico observado de esta manera pudo ser expresado en porcentaje sobre las poblaciones de estas cochinillas.

Los “sínfilos comedores de raíces”, procedentes de las colectas de campo fueron transportados al laboratorio en tubos de ensayo conteniendo suelo y raíces de las plantas de piña. Se observó bajo el microscopio estereoscópico los hábitos alimenticios de estos artrópodos.

\section{Resultados y discusión.}

La mosca $M$. viatrix, que ataca a los frutos, fue el problema entomológico más grave. Los ácaros que viven en las cavidades florales e insectos asociados a la inflorescencia, podrían ser vectores y diseminadores de Fusarium moniliforme y Penicillum funiculosum, aquellos que producen las "manchas negras en los frutos". En este trabajo se consideraron problemas potenciales la "broca de la piña" $S$. megarus y la "cochinilla de la piña" D. brevipes. Julca \& Bello (1994) establecieron que $S$. megarus es una plaga de 
importancia económica, carácter endémico en las zonas de América del Centro y Sur citando los trabajos de Velazco et al. (1968), Py et al. (1987) y Bello (1991).

"Mosca de la piña"

En la Región Neotropical esta especie se registró en Colombia por primera vez en 1991 en San Juan de Río Seco (Cundinamarca). Villalobos \& Luque (2012) mencionan que la especie ya había sido registrada atacando cultivos silvestres en el Perú y Surinam; posteriormente, en 1993 se detectó en cultivos comerciales de 15 municipios de Antioquia afectando hasta el $100 \%$ de las variedades 'Cayena Lisa', 'Manzana' y 'Perolera'. Según Montilla et al. (2008) esta mosca fue detectada en 1998 en plantaciones de piña cultivada en los Estados de Táchira y Trujillo en Venezuela. Asimismo Boscan et al. (2000) registraron la presencia de esta especie en plantaciones de piña en el estado de Carabobo, posteriormente Abzueta et al. (2007) encontraron a $M$. viatrix en el estado de Monegas. El daño observado externamente fue la maduración desuniforme e internamente, la pudrición y presencia de larvas.

En el área de influencia del presente trabajo $M$. viatrix fue citada como M. canopilosum, por Figueroa et al. (1970). Se encontró ampliamente distribuida por toda la zona, en poblaciones de alta densidad, en especial sobre plantaciones abandonadas; se registró como plaga en Centro Toterani (Valle del Perené en Satipo), durante el mes de julio de 1985. Fue un grave problema en el fundo Santa Teresa (Satipo), afectando hasta el 81 \% de la producción en julio de 1985, el ataque fue semejante en "Metraro" (Perené) y "Quimiri Sur" y "Quimiri Centro” (Chanchamayo) entre abril y noviembre. Durante el año 1986, en las evaluaciones realizadas en el Banco de Germoplasma del fundo Santa Teresa, el tipo criollo 'cabezona' resultó el más afectado, recuperándose un promedio de 195.5 moscas por fruto, mientras que en el cultivar criollo 'Manzana' 151 larvas por fruto. En 1987, el comportamiento fue similar aunque la incidencia fue menor. Sus poblaciones aumentaron durante toda la época seca, de mayo a agosto, en épocas de precipitación no se observaron adultos vivos en el campo, las poblaciones probablemente fueron afectadas por hongos entomopatógenos.

Los estudios sobre la biología de $M$. viatrix son escasos, Villalobos et al. (2009) estudiaron la morfología y señalaron que las larvas de esta especie son ápodas, de aspecto vermiforme y de color amarillento, con un par de espiráculos posteriores muy pronunciados y el cuerpo dividido en 11 segmentos que portan pequeñas espículas que ayudan a la locomoción; la pupa es de tipo coarctata de color marrón con 11 segmentos.

En el material estudiado en la zona, se pudo observar en el laboratorio que los adultos son de color oscuro casi negro, ojos de color verde oscuro y

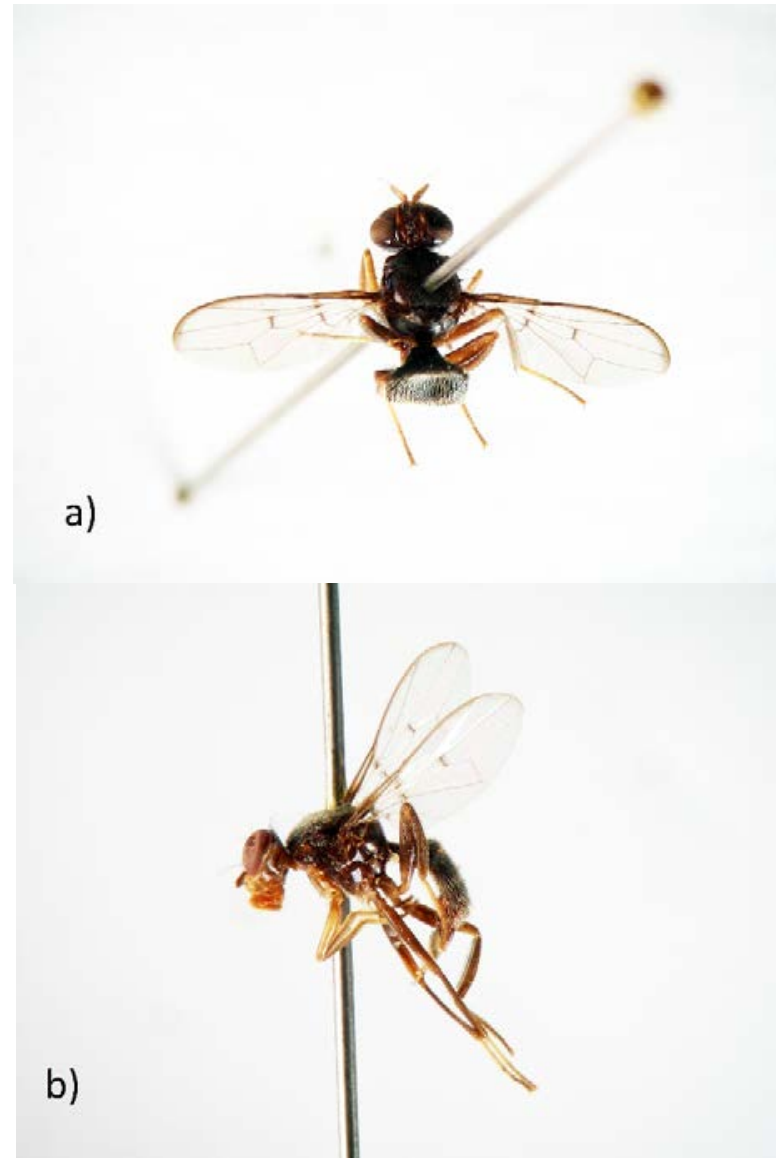

Figura 2. Melanoloma viatrix Hendel. a) Vista dorsal b) vista lateral.

brillante, alas hialinas de venación marcada, midiendo en longitud con un promedio de $5.8 \mathrm{~mm}$ las hembras y $5.4 \mathrm{~mm}$ los machos. El género Melanoloma Loew se caracteriza porque presenta cabeza redondeada más ancha que el tórax, con la frente completamente plana; tórax de aspecto normal, alas con la vena r-m ubicada más allá de la celda discal, ampliamente alejada del extremo de la subcosta; abdomen peciolado cubierto de micropubescencia, como describe Korytkowski (1993), en la Figura 2, se muestran fotografías del material que se conserva en el Museo "Klaus Raven Büller”.

Las hembras adultas de $M$. viatrix atacaron frutos verdes que habían completado su desarrollo, frutos pintones y maduros. En el laboratorio se encontraron en grupos de 5 a 6 larvas, que probablemente se originaron de huevos ovipositados por una hembra por cada grupo en el campo, habiéndose contado grupos de hasta 51 larvas. Las larvas se desarrollaron en grupos dentro y en la periferia del fruto en grupos cerca de la cáscara, tal y como Villalobos \& Luque (2012) mencionan que "el ataque empieza con la oviposición en el fruto, la larva emergida se introduce y se alimenta de la pulpa”. Se observó que la infrutescencia infestada no presentaba síntomas 
externos del ataque cuando las larvas eran pequeñas. Se han encontraron grupos de diferentes estadíos en la misma infrutescencia, lo que significa que fueron puestas en tiempos distintos y que esta especie no discrimina los hospedadores que fueron utilizados anteriormente por otras hembras. En infestaciones fuertes de campos abandonados, las larvas ocuparon todo el fruto incluyendo la base de la corona y el pedúnculo; se recuperaron más de 400 larvas por fruto en julio de 1985 en Satipo. Las larvas que completaron su desarrollo emergieron de la fruta sobremadura o podrida en el campo. Pupan en el suelo o en los restos de la fruta. En un estudio de cría masiva en laboratorio realizado por Villalobos \& Luque (2012) se encontró que el ciclo bajo condiciones artificiales tiene una duración de unos 57 días (huevo $=6$ días, larva $=34$ días y pupa $=17$ ) y fase adulta llegaba a vivir hasta 92 días.

En las colecciones realizadas en el fundo Santa Teresa (Satipo) en 'Cayena Lisa' en julio de 1985, se encontró que el $81 \%$ de la fruta verde y pintona fue atacada por la mosca. En disecciones de los frutos en el laboratorio el promedio de larvas por fruto pintón fue de 27 y por fruto verde de 15.5 (Tabla 1). No existieron diferencias significativas entre ambos tratamientos -pintón y verde- en el número de grupos de larvas del mismo estadío -asumiendo que cada grupo proviene de una puesta-; así, se encontró un promedio de 2 grupos de larvas en frutos verdes y 1.9 en frutos pintones, lo que significa que las hembras atacaron sin preferencias tanto frutos verdes como pintones. El mayor número de larvas en frutos pintones tal vez se podría explicar, que debido al tipo de medio -azucares, pH., etc. - en estos frutos podría ser muy favorable, permitiéndoles expresar una mayor tasa de supervivencia. El $50 \%$ de los frutos de esta colecta presentaron gomosis (Tabla 2). Es probable que esta afección en este caso pudo haber sido causada por deficiencia de boro, como sucedió de manera generalizada en Chanchamayo y Satipo (Bello, 1989), en los casos de gomosis en frutos sin larvas y con menor cantidad de resinas. En frutos con larvas pudo ser originada por la actividad de las larvas.

Se registró hasta el $81 \%$ de las infrutescencias afectadas en la producción de 'Cayena Lisa' en el fundo Santa Teresa en Satipo, y casi la totalidad de los

Tabla 1. Promedio de larvas y grupos de larvas de Melanoloma viatrix Hendel obtenidas por fruto de piña 'Cayena Lisa'. 27 de julio de 1986, 18 frutos (33 Kg.). Satipo, Junín (Perú). C.V. = coeficiente de variabilidad. Fuente: Arellano, 2001.

\begin{tabular}{llccc}
\hline & Fruto & Promedio & Varianza & C.V. \\
\hline \multirow{2}{*}{ Larvas } & Pintón & 27 & 13.59 & 13.65 \\
& Verde & 15.5 & 10.49 & 20.08 \\
Grupos & Pintón & 2 & 0.89 & 47.28 \\
de larvas & Verde & 1.9 & 1.57 & 66.11 \\
\hline
\end{tabular}

Tabla 2. Porcentajes de lesiones en los frutos 27 de julio de 1986, 18 frutos (33 Kg) en Satipo, Junín - Perú. Fuente: Arellano, 2001.

\begin{tabular}{lc}
\hline $\begin{array}{l}\text { Lesiones en los } \\
\text { frutos }\end{array}$ & Porcentajes \\
\hline Con gomosis & 50 \\
Con manchas negras & 25 \\
Con gomosis y & 12.5 \\
manchas negras & \\
\hline
\end{tabular}

frutos de 'Samba de Chanchamayo' examinados en diferentes zonas de colección presentaron ataque de mosca en la época seca del año 1985. En los años 1986 y 1987 la incidencia fue menor.

Sobre el control efectuado por enemigos naturales, se observó que al emerger las larvas desarrolladas de los frutos infestados, estas son atacadas por una especie de la familia Staphylinidae (Coleoptera) y otras dos Euborellia spp. (Dermaptera: Anisolabididae). No se recuperaron parasitoides, sin embargo, en Trujillo - Venezuela, Montilla et al. (2007) señalaron la presencia de un parasitoide de pupas de $M$. viatrix determinado como Spalangia drosophilae Ashmead (Hymenoptera: Pteromalidae) ofreciendo breve información sobre parasitismo.

En condiciones de laboratorio, en una cría de 969 larvas de último estadío recuperadas de colecciones de frutos del campo en Satipo en julio de 1985, el 40.44 \% de los especímenes, entre larvas y pupas, resultaron afectados por un hongo entomopatógeno no determinado. El micelio, que fue de color blanquecino, emergió por la región caudal y fructificó sobre el pupario, causando la muerte de las moscas. El interior del pupario se encontró ocupado enteramente por dicho micelio. El exceso de humedad producido por el fruto en descomposición en las crianzas, pudo haber favorecido el desarrollo de este patógeno y es probable que sea un buen controlador en épocas de mayor precipitación.

Se realizaron ensayos de control cultural de la mosca, en los lotes experimentales del fundo Santa Teresa; en concreto, la limpieza del campo al momento de la siembra y durante la fructificación, eliminando los frutos sobremaduros y realizándose además labores de fertilización. La eliminación de plantaciones abandonadas cercanas que constituyen potencialmente grandes reservorios de la mosca, contribuyeron a la disminución de las poblaciones, sobre todo en época seca. Sin embargo, los hábitos saprofitos y el hábitat de la mosca en condiciones de bosque, hacen, necesario realizar el manejo integrado que involucre todas las técnicas posibles de control.

\section{Ácaros de la piña}

Durante el periodo de evaluación se registraron “ácaros de la piña” en la inflorescencia, frutos en formación, frutos maduros y en toda la planta; en concreto, sobre plantas de 'Samba de Chanchamayo' en Quimiri (Chanchamayo), Metraro, Centro Toterani 
(Perené), en Satipo, sobre las plantas de 'Rosada', 'Chuncha’, 'Río Negro’ y ‘Cayena Lisa’.

Los ácaros de la piña se presentaron durante todo el año, pero su mayor abundancia fue en el periodo seco, en especial en el mes de julio. Poblaciones muy altas fueron observadas en plantaciones abandonadas y sobre las plantas afectadas por la intensa sequía. En los cultivos se observaron dos especies (A y B) de ácaros. La especie A presentó una coloración amarillo pálido a simple vista; los individuos de esta especie se encontraron en toda la planta; mayor abundancia de ellos se observó en los frutos sobremaduros; las plantas que sufrieron sequía fueron muy afectadas. La especie B de un color gris azulado, se localizó en colonias dentro de las cavidades de las flores individuales. La incidencia de ambas especies de ácaros fue en la época seca de mayo a agosto. El daño directo fue sólo apreciable en plantaciones que sufrieron sequías intensas o fueron abandonadas. Las altas densidades en las poblaciones provocaron lesiones en las axilas y bordes de las hojas, en las cavidades de las flores individuales y en los "ojos" de las infrutescencias. Cuando los ataques fueron muy fuertes ocasionaron la muerte de la planta.

Estos ácaros de forma indirecta tendrían una gran importancia económica. Estarían implicados en la contaminación con dos patógenos Fusarium moniliforme y Penicillum funiculosum, los cuales producen diversas enfermedades, ya sea que se trate de manchas negras más o menos blandas y extendidas a nivel de las cavidades del ovario, o de formaciones "corchosas" epidérmicas o internas.

Estas enfermedades causadas por estos patógenos se encuentran ampliamente distribuidas por toda la zona, siendo su mayor incidencia marcadamente estacional - en las infrutescencias de la época seca -, que coincide con la alta densidad de ácaros e insectos en las inflorescencias y frutos en formación.

Como observaron Bolkan et al. (1978), los patógenos penetran al fruto mucho antes de la formación de éste, por las aberturas naturales en el preciso momento en que se abren las flores individuales. La abundancia de ácaros y la diversidad de insectos que frecuentemente visitan las cavidades florales, parecen intervenir en la contaminación, este hecho fue comprobado en Sudáfrica por Le Grice y Marr (1970), quienes encontraron dos especies involucradas: el ácaro Steneotarsonemus ananas (Tryon) y la "cochinilla" Pseudococcus brevipes (Petty). Posteriormente Rohbach et al. (1981) en Hawai y Py et al. (1984) cita que en la Isla de la Reunión registraron otro ácaro Thyreophagus putrescentiae (Schrank). En Chanchamayo y Satipo los ácaros observados probablemente realizarían funciones análogas a la de las especies antes mencionadas.

Por su parte se encontró a la abeja Trigona almalthea (Oliver) (Apidae: Meliponini), que corta y

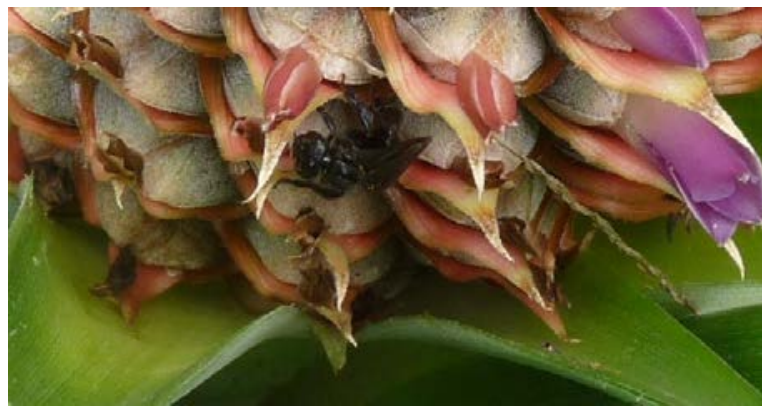

Figura 3. Trigona amalthea, en una bráctea floral. Fotografía G. Arellano.

tritura los pétalos de las flores (Figura 3). La "cochinilla" Dysmicoccus brevipes (Cockerell) cuando se localiza en las inflorescencias y frutos, Strymon megarus (Goardt) y otros insectos como hormigas, podrían tener relativa importancia. No se pudo comprobar si estas especies sirven sólo de vectores de los patógenos, o si ellas permiten su penetración a través de las heridas que podrían provocar en el fondo de la copa floral, o si los patógenos por si mismos penetran a través de los conductos naturales; este comportamiento debería ser investigado en nuevos proyectos.

Las manchas comúnmente encontradas en Chanchamayo y Satipo, coinciden con las descritas por Py et al. (1984) causada por los patógenos Penicillum funiculosum y Fusarium moniliforme. La existencia de estos patógenos fue comprobada gracias a muestras analizadas en el Departamento de Fitopatología de la Universidad Nacional Agraria La Molina (UNALM) y el Institut de Reherche sur les Fruits et Agrumes de Francia (IRFA).

La "mancha negra” es la anomalía que mayormente se presentó en Chanchamayo y Satipo. En observaciones realizadas en un centro de acopio para la industria y en camiones de transporte para la fruta en julio de 1985, se encontró el $31 \%$ de la producción afectada. En este caso, en los frutos no se observó ningún tipo de síntoma externo de la enfermedad. Las manchas se observaron en el interior del fruto y en la periferia. La coloración es variable, las manchas pueden ser amarillo oscuro translúcidas y muy pequeñas, manchas más grandes cuya coloración se vuelve marrón claro, manchas marrón oscuro que no desborda los tejidos del "ojo", y manchas marrón y negras que desbordan de manera más o menos amplia los tejidos del "ojo". Tanto en frutos de 'Samba de Chanchamayo' como en 'Cayena Lisa' se encontraron este tipo de afecciones. Hasta el $35.5 \%$ de los frutos de 'Cayena Lisa', en Satipo, fueron afectados en julio de 1986. Sin embargo, en la misma época más del 50 \% de los frutos de 'Samba de Chanchamayo' procedente de Quimiri resultaron "manchados". En 1987, el 90 \% de los frutos examinados procedente de 
estos lugares al centro de acopio presentaron "manchas negras".

Con respecto a las manchas "bolsas de cuero" o "leathery pocket". Este tipo de mancha, Hepton \& Anderson (1968), Rohrbach \& Pfeiffer (1976a, 1976b) y Muorichon (1982) mencionan que podría producirse debido a infestaciones precoces, justo antes de la apertura floral. La penetración del patógeno se originaría principalmente por los canales nectaríferos, a partir de los cuales el micelio podría alcanzar los canales del estilo del eje placentario y las cavidades ováricas; en este estado de desarrollo el fruto reacciona formando una barrera corchosa que bloquea la penetración del hongo en un estado más avanzado. Esta reacción origina dichas machas; la mancha es producida por la suberificación de las paredes de las cavidades carpelares lo que da a la lesión una consistencia de cuero (Py et al., 1984). Estas manchas son menos frecuentes en los diferentes cultivares de piña y han sido observadas en 'Cayena Lisa' y 'Samba de Chanchamayo'.

El "fruto corchoso", se observó en plantaciones abandonadas y en aquellas con sequía intensa. Esta anomalía se presentó como una suberificación extrema entre los "ojos", acompañada por grietas finas transversales de los sépalos o brácteas. Cuando muchos "ojos" vecinos son afectados se entorpece el desarrollo resultando malformaciones en el fruto (Py et al., 1984).

La incidencia económica de las "manchas" puede ser considerable. En el caso de frutos destinados a la industria, las rodajas enteras constituyen el producto noble de las conservas y generalmente el más rentable. En el caso de los frutos destinados al mercado fresco la ausencia habitual de síntomas externos hizo imposible seleccionar la fruta. Cuando las manchas son muy numerosas y el porcentaje de frutos afectados es muy alto como el caso de la zona de Quimiri, en 1986-87 (hasta el $90 \%$ ), la fruta no fue comercial.

Se realizó un control cultural, en la parcela de experimentación con 'Cayena Lisa', con las siguientes actividades para disminuir la incidencia de manchas en los frutos. Se favoreció el crecimiento de las plantas para disminuir la incidencia de ácaros. Se eliminó el material vegetal en descomposición - restos de plantas y frutos infectados - en épocas lluviosas ya que éstos pudieron constituir una fuente de propagación del inóculo. Se procedió a la eliminación de plantas sensibles a los patógenos en los bordes del cultivo. En los lugares donde fue posible, se efectuó el riego antes de la floración en épocas secas, para así reducir el tamaño de las aberturas naturales de las inflorescencias, disminuyendo las posibilidades de contaminación. Bello et al. (2008) realizaron trabajos de protección mecánica de la inflorescencia y uso de trampas caseras, logrando controlar con éxito los insectos que actúan como vectores de patógenos. Para evaluar el efecto del control cultural se dejaron parcelas con manejo tradicional sin control y al momento de la cosecha se cuantificaron los daños de la mancha; igualmente en la protección mecánica se protegieron frutos con bolsas de polietileno a diferentes momento del desarrollo de la infrutescencia, parcelas con trampas caseras, parcelas testigo sin protección y sin trampa; a la cosecha, se evaluaron frutos con y sin mancha obteniéndose el número de frutos con y sin mancha y el porcentaje de la mismas (Bello \& Julca 2005; Bello et al., 2008).

Broca de la piña

Esta especie ha sido registrada en el presente trabajo en toda la zona de Chanchamayo - Satipo desde el año 1986. Según Py et al. (1984), citada como $T$. basilides, se encuentra distribuida por toda América Latina incluyendo el Caribe con excepción de Trinidad; no se encuentra en otros continentes. Da Costa Lima (1950) señala que esta especie ha causado daños fuertes en Trinidad y Costa Rica.

La "broca de la piña” (Figura 4) se presentó con mayor incidencia en el año 1986, caracterizado por su extrema sequía, registrándose en el mes de mayo 31.4 mm y junio $11 \mathrm{~mm}$ de precipitación, considerando que en promedio entre los años 1983-1987 en el mes de mayo hubo $105 \mathrm{~mm}$ y en el mes de junio $89 \mathrm{~mm}$. Arellano (2001) indica que, es probable que estas condiciones incrementaron las poblaciones de $S$. megarus. Los primeros huevos de esta especie se observaron en abril sobre las inflorescencias al término de la época de mayor precipitación. Las primeras larvas se registraron en mayo en Satipo, sobre inflorescencias y frutos tiernos de 'Cayena lisa', resultando afectados el $11 \%$; en julio, se registraron frutos con perforaciones $y$ deformaciones con exudaciones gomosas, resultando afectados el $60 \%$ de la producción de este cultivar; en septiembre, el ataque disminuyó, pero aún se recolectaron larvas y se observó gran cantidad de restos de huevos. En octubre no se observaron puestas nuevas ni larvas. Durante el año 1987 se registró un ataque muy bajo. Estas observaciones coinciden con las descritas por Py et al. (1984) para Brasil. La plaga aparece de abril a octubre y requiere condiciones ambientales especiales para llegar a un daño económico, como años de extrema sequía en Satipo.

Las larvas de $S$. megarus barrenaron la inflorescencia y frutos de reciente formación. Al desarrollar el fruto atacado, como reacción, produce exudaciones gomosas a través de las perforaciones hechas por las larvas, deformaciones en los frutos, pudrición o infecciones secundarias como manchas negras de Fusarium moniliforme y Penicillum foniculosum. Se registraron frutos hasta con tres perforaciones. El fruto atacado por $S$. megarus no tiene valor comercial. Como se observa en la Tabla 3, 'Cayena Lisa' es el cultivar que resulta más seriamente afectado. 


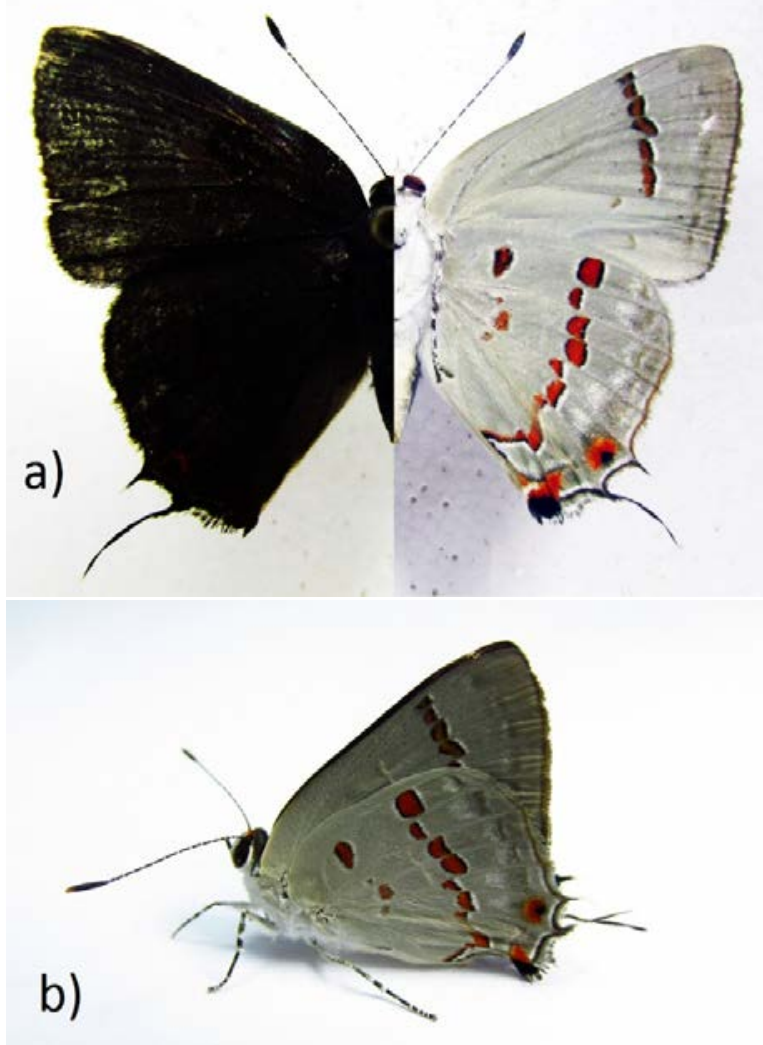

Figura 4. Strymon megarus (Goardt). a) Visión dorsal/ventral de la hembra. b) Hembra tras la emergencia reciente de la pupa, procedente de Chanchamayo en piña ‘Golden’. Fotografías tomadas por Clorinda Vergara, a partir de material registrado producto de una crianza en gabinete en el fundo La Bretaña en San Ramón realizada por S. Bello.

Por su parte se confirmaron las siguientes características morfológicas mencionadas por Fonseca (1973), presenta el aspecto dorsal del cuerpo, las alas anteriores y posteriores de color gris oscuro. Las alas posteriores presentan dos manchas de color naranja, con bordes blancos y dos pares de apéndices filamentosos. La parte ventral del cuerpo es blanca y el aspecto ventral de las alas es gris claro con una serie de manchas rojizas paralelas cerca al borde de las alas. También se ha observado, tal y como describe Harris (1927), que la hembra deposita sus huevos generalmente en la base de una bráctea floral después de la apertura de la primera flor individual. Los huevos son de color blanco verdoso, finamente reticulados y ligeramente comprimidos en su base y con una depresión en la parte superior que se torna rojiza poco antes de la eclosión (Figura 5a); miden más o menos $0.5 \mathrm{~mm}$ después de la eclosión, la larva, de color blanco cremoso, penetra generalmente por la base carnosa de la bráctea principal, devora las piezas florales y se introduce en el eje floral o fruto tierno produciendo galerías. Al completar su desarrollo emerge de la fruta en formación, con un integumento rugoso de coloración rosada (Figura 5b) y dos bandas dorso-abdominales de color rosado más intenso; se transforma en pupa generalmente en el envés de las hojas de la base de la planta (Figura 5c).

En condiciones de laboratorio el periodo pupal duró 12 días, y el ciclo se completó entre 29 a 32 días. Los adultos podrían estar implicados en la

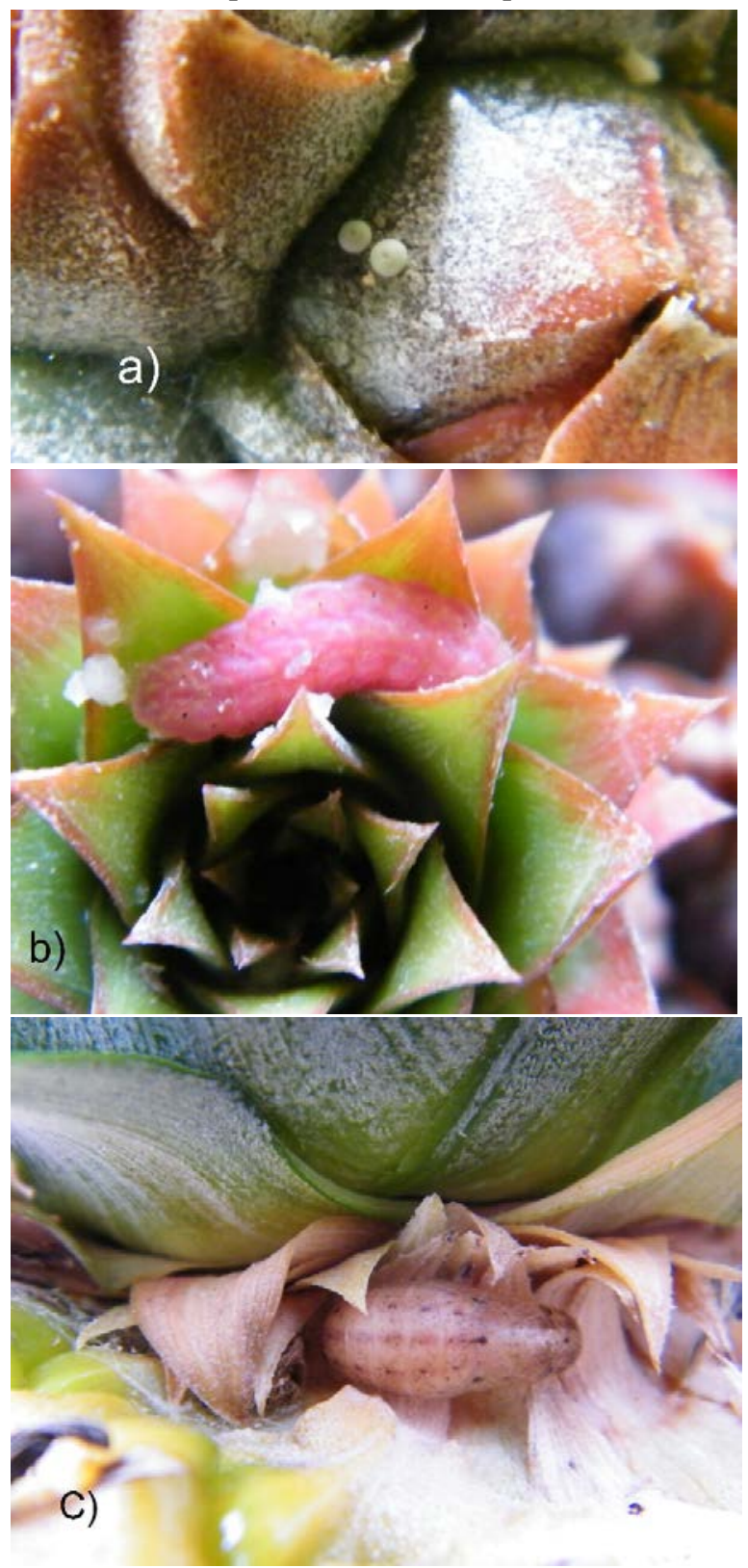

Figura 5. Strymon megarus Goardt, a) Huevos sin eclosionar, puestos sobre una bráctea floral. b) Larva alimentándose y completando su desarrollo. c) Pupa protegida en el envés las hojas de la planta de piña 'Golden'. Fotografías tomadas por Segundo Bello en San Ramón, Chanchamayo. 
diseminación de las esporas de Fusarium moniliforme y Penicillum foniculosum; en disecciones de frutos con ataque de $S$. megarus se encontraron manchas de F. moniliforme rodeando la herida causada por la larva.

Según Py et al. (1984), algunas bromeliáceas silvestres que crecen en el bosque o lugares cercanos a la plantación, al término de la campaña pueden servir de hospederos alternos a esta especie.

En el laboratorio emergió un parasitoide de las pupas: Spilochalcis sp. (Hym., Chalcididae) (Figura 6). Harris (1927), señaló la presencia del parasitoide Heptasmicra sp. sobre las larvas y un depredador Polistes rubiginosus St. Farg. Da Costa Lima (1950) menciona que las larvas son atacadas por Tetrastichus sp. y por la mosca Zygosturmia heinrichi Lima, en Brasil.

El cultivar 'Cayena Lisa' fue susceptible al ataque de $S$. megarus mientras que la piña 'Samba de Chanchamayo’ no resultó afectada, así como tampoco los otros cultivares de piña de la zona (Tabla 3) estos resultados fueron corroborados por Bello et al. (1997). En estas parcelas se recomendó un control cultural consistente en la eliminación de frutos infestados por $S$. megarus, así como uniformizar la siembra al inicio de la precipitación, entre setiembre y octubre, para que la floración de la primera cosecha se logre en épocas lluviosa en las que no incide la plaga.

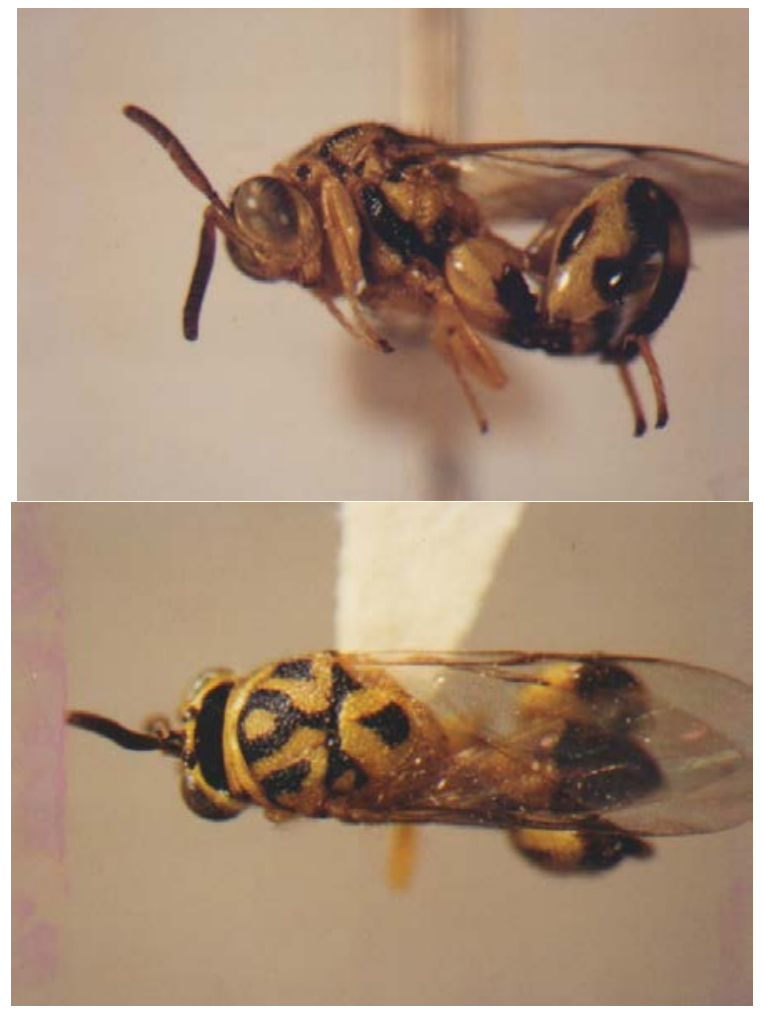

Figura 6. Adulto de Spilochalcis sp. (Hym., Chalcididae). Fotografías tomadas del material procedente del fundo Génova. Arellano (2001).
Tabla 3. Porcentaje de daño ocasionado por Strymon megarus (Goardt) en diferentes cultivares de piña del germoplasma del fundo Santa Teresa de Satipo. 17 de julio de 1986. Fuente: Arellano, 2001.

\begin{tabular}{lc}
\hline Cultivares y/o tipos de piña. & \% de daño \\
\hline 'Cayena Lisa' & 60.0 \\
'Samba de Chanchamayo' & 5.0 \\
'Rosada' & 1.7 \\
'Lagarto' & 0 \\
'Azúcar' & 0 \\
'Roja española' & 0 \\
'Manzana' & 0 \\
\hline
\end{tabular}

\section{Cochinilla harinosa}

Los miembros de esta especie están distribuidos por toda la zona; han sido recolectados en Satipo, Metraro, Quimiri y Pampa El Carmen. Sus poblaciones se incrementaron en épocas lluviosas y al inicio de la precipitación, pero pudieron presentarse durante todo el año. Se localizaron generalmente en las raíces del cultivo y en la época seca se les observó también en la parte aérea de las plantas, como ocurrió en junio de 1985 y 1986.

Pueden infestar grandes áreas debido a que establecen relaciones de protocooperación con hormigas que favorecen su dispersión, de los géneros Camponotus spp., Crematogaster spp. y otros, como se observó en Metraro en noviembre de 1985.

En Centro Toterani, Metraro y Quimiri fue común observar en las chacras áreas de regular tamaño con plantas de crecimiento retardado, cuyas raíces, se encontraron totalmente infestadas por $D$. brevipes.

Las "cochinillas de la piña" pueden localizarse en las raíces, tallos, las hojas, inflorescencias y frutos (Figura 7). Se alimentan succionando la sabia de las plantas, pudiendo causar amarilleamiento de las hojas, defoliación, retardo de su crecimiento y en algunos casos la muerte de la planta. Las especies $D$. brevipes y $D$. neobrevipes Beardsley, son indicadas también como vectores primarios del virus de la marchitez (PMWaV) que causa la "enfermedad de Wilt” (Py et al., 1984), asociada al "piojo harinoso de la piña” en cultivares de piña hawaiana (González-Hernández et al., 1999). Esta enfermedad se ha citado en cultivares de importancia en 'Cayena Lisa' al sur de China (Sether et al., 1998; Qin et al., 2011). Hasta hoy, no existe información de esta afección en la zona. $D$. brevipes, conocido por los agricultores brasileños como el "áfido blanco" o “piojo blanco", está presente en todos los cultivares de piña de Brasil, y se considera como una de las principales plagas de la piña. El daño de la plaga llegó al $30.9 \%$ en las plantaciones de 'Cayena Lisa' en Paraíba (Choairy et al., 1984); la pérdida, sin embargo, puede alcanzar hasta 50\%, de acuerdo con Py et al. (1984) y Lara et al. (2015).

La población de $D$. brevipes más numerosa se establece en las raíces ocasionando el mayor daño, 
haciendo difícil su control. En forma indirecta podrían provocar la diseminación de la enfermedad de "Wilt" y de los patógenos $F$. moniliforme y $P$. foniculosum, responsables de las manchas en los frutos. La asociación de $D$. brevipes y la planta de piña, es el resultado de condiciones favorables como por ejemplo la nubosidad prolongada, que permitirían la aparición natural de la enfermedad. Se manifiesta por una sucesión de síntomas, los primeros localizados en el sistema radicular, después aparecen en todas las hojas y eventualmente ataca los órganos de reproducción, lo que hace imposible la recuperación de la planta (Py et al., 1984).

Aunque no se ha comprobado la existencia de esta enfermedad en la zona, permanece como un peligro potencial debido a la existencia de $D$. brevipes, condiciones ambientales favorables y la introducción de clones de 'Cayena Lisa’ susceptibles.

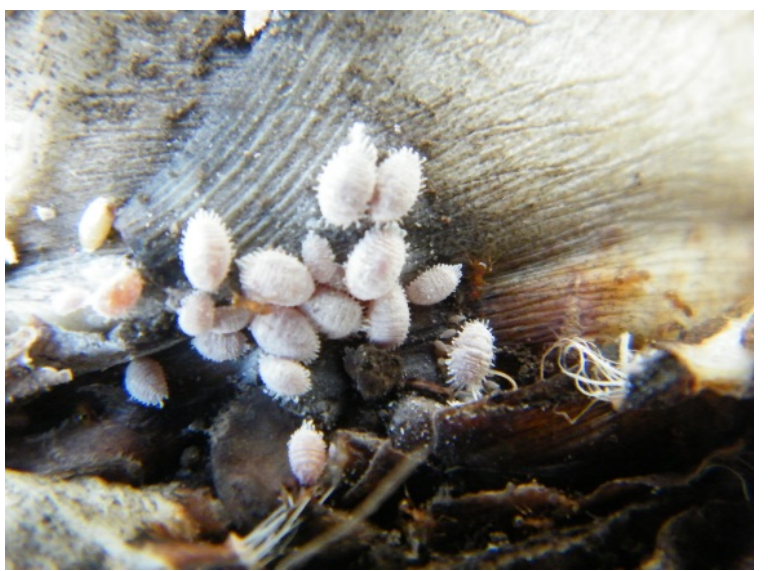

Figura 7. Dysmicoccus brevipes (Cockerell) (Hem., Pseudococcidae), en las axilas de las hojas de piña 'Golden' en Chanchamayo, en asociación con algunas especies de Formicidae. Fotografía Segundo Bello.

González-Hernández et al. (2005) encontraron que Anagyrus ananatis Gahan (Hymenoptera: Encyrtidae) era el enemigo natural más común de $D$. brevipes en las plantaciones de piña de Hawai. También se cita la que las cochinillas $D$. brevipes son parasitadas por Anagyrus coccidivorus Dozier, A. pseudococci Girault, (Hymenoptera: Encyrtidae), Baeoplatycerus viriosus De Santis, Hambletonia pseudococcina Compère, (Hym: Encyrtidae) y Anastatus anonatis Gahan, (Hym: Eupelmidae.); son depredadas por larvas de Pseudiastata brasiliensis Lima, $P$. nebulosa Coquillett, (Diptera: Drosophilidae) y Ceratobaeus sp. (Hym: Scelionidae); y larvas y adultos de Hyperapsis quinquenotata Mulsant, Cryptolaemus montrouzieri Mulsant y Scymnus sp. (Coleoptera: Coccinellidae), presentes la mayoría de ellas en Brasil (Menezes, 1973; Santa Cecilia \& Reis, 1985; Lara et al., 2015). Cevallos \& Granada (2004), reportan la presencia de Hambletonia pseudococcina en Cuba sobre una especie del género Dysmicoccus, presentes en el café y banano en julio del 2003, haciendo énfasis que esta especie es parasitoide de $D$. brevipes que se distribuye en países como: México, Estados Unidos (Florida), Brasil, Venezuela, Colombia, Argentina, Puerto Rico, Jamaica y Taiwán.

En toda la zona evaluada es raro encontrar $D$. brevipes en la parte aérea de las plantas; existe un eficiente control biológico natural ejercido por el parasitoide $H$. pseudococcina (Hym., Encyrtidae) que registró un parasitismo entre el 57\% al 70\%.

Para el control, se realizaron las siguientes actividades culturales en las parcelas experimentales del fundo Santa Teresa: destrucción de residuos del cultivo anterior y malezas que puedan hospedar "cochinillas", recolección selectiva de hijuelos libres de "cochinilla", por su parte la eliminación selectiva de los hospedadores alternos y el riego es otro factor que contribuyó al control de estos insectos en estos lotes. El riego abundante causa una reducción significativa de la infestación de plagas debido posiblemente a su remoción por el lavado, muerte por ahogamiento y la acción de entomopatógenos que se incrementan por la alta humedad (Santa Cecília \& Rossi, 1991).

$\underline{\text { Sínfilos comedores de raíces }}$

Estos artrópodos fueron registrados (Figura 8), en noviembre de 1985 en Metraro y Satipo. En marzo de 1986 y 1987 nuevamente en Satipo. Generalmente incrementaron sus poblaciones a fines de la época de mayor precipitación e inicio de la precipitación. También, los suelos sueltos son condiciones favorables para el desarrollo de esta plaga.

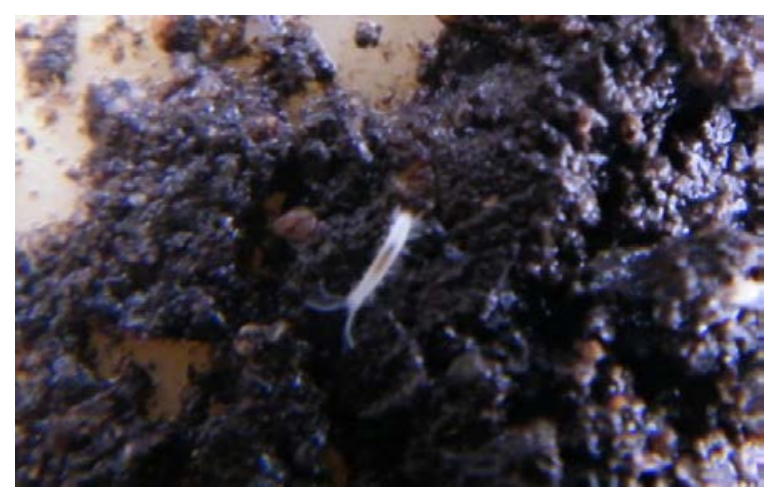

Figura 8. Especie de Symphyla, en raíz de piña 'Golden' en Chanchamayo. Fotografía tomada por S. Bello.

En las crías de laboratorio se determinó que estas especies, se alimentan de las raíces de las plantas de piña, causando daños en el extremo de las raíces secundarias, produciendo en ellas hendiduras a manera de un pequeño cráter.

Son de cuerpo vermiforme achatado dorsoventralmente, de color blanco, sin ojos, un par de antenas largas y doce pares de patas. Miden de 2 a 4 
mm, son de movimientos rápidos y presentan mayor actividad en las primeras horas de la mañana. Py et al. (1984; 1987), mencionan que el ataque de Symphyla perturba la absorción de elementos nutritivos y como consecuencia, el normal crecimiento de las plantas causando una acción represiva sobre el rendimiento. El ataque de estos artrópodos no tiene una incidencia económica en la zona y pueden ser controlados con labores culturales.

Otros insectos que atacan la piña

En 1981, Raven registró la especie Metamasius hemipterus L. (Col., Curculionidae) registró la especie cuyas larvas causan daño a los frutos de piña. Recuperó adultos en el laboratorio de frutos con daño, colectados en Chanchamayo en junio de 1981, en donde la plaga causó daños de importancia económica, según las observaciones de la libreta de registro del Museo de Entomología "Klaus Raven" (Arellano, 2001). Esta especie fue registrada nuevamente en Metraro en noviembre de 1985, sobre tres frutos en una ha de 'Samba de Chanchamayo'.

La abeja Trigona almalthea, observada en altas densidades, julio de 1987, en Satipo sobre la plantación 'Cayena Lisa' durante la floración, también ha sido registrada en varias colecciones 'Samba de Chanchamayo'. Los miembros de esta especie cortan los pétalos de las flores, los trituran y extraen los jugos celulares quedando los restos de los pétalos sobre la bráctea principal de la flor. También colectan el néctar de las mismas flores. Los frutos que se forman de las inflorescencias atacadas presentan manchas negras. Esta especie también fue observada en cítricos cortando y triturando las hojas.

Por su parte es común observar a Largus balteatus (Hem., Largidae) alimentándose en las inflorescencias y frutos de piña, se registró en Santa Teresa y Metraro (Satipo).

Una especie de chinche Phthiacnemia picta (Drury) (Hem., Coreidae) se colectó en abundancia una sola vez en enero de 1986. Los especímenes colectados son una nueva cita para el Perú, la determinación fue hecha por L. Cruces. Los adultos y ninfas de últimos estadios se localizaron y se alimentaron en el envés de las hojas. Las ninfas de primeros estadios lo hicieron en el cogollo y la base de las hojas. Estas observaciones se realizaron en la plantación de 'Cayena Lisa' en Satipo. Esta especie ha sido registrada también en papaya y café, en Chanchamayo.

Finalmente, Annona fuscata Carvalho \& Schaffner (Hem., Miridae), se presentó de mayo a diciembre en Chanchamayo y Satipo sobre las plantas de piña y cafetos; también en la hierba de las plantaciones de papaya, café y cítricos. Por su parte Anasa bellator (F.) (Hem., Coreidae). Se presentó en palto, piña y papaya de marzo a setiembre. Hypselonotus fulvus (De Geer) (Hem., Coreidae) se registró durante todo el año en las plantaciones de cítricos y en los paltos, atacó a las flores y a los botones florales, también en macadamia y piña. Hypselonotus interruptus (Hem., Coreidae) apareció en plantaciones de piña y café, mayormente de mayo a junio. Leptoglossus sp. (Hem., Coreidae) se halló en cítricos y piña, de febrero a mayo. Leptocorisa sp. (Hem. Alydidae) mayormente se encontró en campos de cítricos con mayor abundancia sobre la hierba; fue registrada en cultivos de papaya y piña durante todo el año.

\section{Conclusiones.}

1. La “mosca de la piña" Melanoloma viatrix Hendel, ataca a los frutos de la piña y es el problema entomológico más grave.

2. Los ácaros que viven en las cavidades florales e insectos asociados a la inflorescencia, podrían ser vectores y diseminadores de Fusarium moniliforme y Penicillum foniculosum que producen las "manchas negras en los frutos".

3. Actualmente la "broca de la piña" Strymon megarus y la "cochinilla de la piña" Dysmicoccus brevipes (Cockerell) son problemas entomológicos importantes de la piña en la Selva Central.

\section{Dedicatoria y agradecimientos.}

Este trabajo está dedicado a la memoria del Dr. Klaus Raven Buller gestor del proyecto inicial y al Dr. Cheslavo Korytkowski por su colaboración en la determinación de especies. Agradecimiento al Mg. Sc. Luis Miguel Cruces por su colaboración en la determinación de especies, y a todos los que de alguna manera apoyaron del trabajo de campo desde 1983 hasta 1987 en el fundo Génova y en el Museo de Entomología “Klaus Raven Büller” de la UNALM.

\section{Literatura citada.}

Abzueta O., Mark D., Rodríguez G., Vásquez L., García A., Delgado J. \& Miglorie R. 2007. Detección y distribución del gusano de la piña (Melamoloma viatrix Hendel) en el estado de Monagas, Venezuela (Diptera: Richardiidae). In "XX Congreso Venezolano de Entomología". Memorias San Cristóbal, 22 al 26 de julio de 2007. San Cristóbal, Táchira Venezuela.

Arellano G. 2001. Evaluación de plagas en Café, Papayo, Piña, Palto, Plátano y Cítricos en Chanchamayo y Satipo. Tesis para optar el grado de Magister Scientiae. Escuela de Post Grado Universidad Nacional Agraria la Molina. Lima - Perú. 194 pp.

Bello S. 1989. El Cultivo de la piña. (Ananas comosus L. Merr) en la Selva Central del Perú y algunos estudios realizados para mejorar la tecnología. Trabajo Profesional para optar el Título de Ingeniero Agrónomo. Universidad Nacional Agraria La Molina. 115 pp.

Bello S. 1991. El cultivo de la piña en la Selva Central del Perú. Informe técnico No 15 INIAA-PtCT. Lima 46 pp.

Bello S., Julca A. \& Villachica H. 1997. Resistencia de cultivares de piña a la "broca de la fruta" Thecla basilides Geyer en Chanchamayo - Perú. Acta Horticulturae (ISHS). 425: 187 - 191.

Bello S., Julca A. \& Villachica H. 1997. Mancha de la fruta de piña tipo galerías asociada a Melanoloma 
canopilosum Hendel. Acta Horticulturae (ISHS). 425: $493-500$.

Bello S. \& Julca A. 2005. Mechanical protection of 'smooth cayenne' pineapple (ananas comosus L. Merr.) inflorescence and fruit, and its effect on 'fruit rot' in chanchamayo - Perú. Acta Horticulturae (ISHS). 666: 241-246

Bello S., Villachica-León H., Villachica-Vivanco H. \& Julca A. 2008. Efecto de la protección mecánica de la inflorescencia y el uso de trampas caseras en el control de la mancha de la fruta de la piña en la Selva Central del Perú. Proc. Interamer. Soc. Trop. Hort. 52: 88-92.

Bolkan H.A., Dianese J. C. \& Cupertino F. P. 1978 Chemical control of pineapple fruit rot caused by $F$. moniliforme var. subglutinans Plt. Dis. Reprt. 62(9): 822 - 824.

Boscan N., Rosales C. \& Godoy F. 2000. La mosca del fruto de la piña Melanoloma viatrix (Diptera: Richardiidae) nuevo insecto plaga en Venezuela. Agronomía Trop. 50(1):135-140.

Callaghan C.J., Casgrande M.M., Lamas G., Mielke O.H.H., Pyrcz T.W., Robbins R.K., \& Viloria A.L. 2004. Atlas of Neotropical Lepidoptera. Checklist: Part 4A, Hesperoidea - Papilionoidea. Assion for Tropical Lepidoptera by Scientific Publishers, Gainesville.

Cevallos M.R. \& Granada C. 2004. Hambletonia pseudococcina Compere (Hymenoptera: Chalcidoidea: Encyrtidae): new report in Cuba. Letter to the editor. Rev. Protección Veg. 19(1): 70.

Combe I. \& Zapata M. 1964. Cursillo de Entomología Tropical. Universidad Nacional Agraria La Molina. Documento mimeografiado. 9 pp.

Coppens d'Eeckenbrugge, G. \& Leal F. 2003. Morphology, Anatomy and Taxonomy. In: Bartholomew, D. P., Paull, R. E. and Rohrbach, K. G. (eds.): The Pineapple: Botany, Production and Uses. CAB International, Wallingford (Great Britain). 301 pp.

Choairy S.A., de Oliveira E.F. \& Sanches N.F. 1984. Pragas do abacaxi e seu controle. João Pessoa: Embrapa/EMEPA, (EMEPA. Circular Técnica, 2). 22 pp.

Da Costa Lima A. 1950. Insectos do Brasil Lepidopteros. 2da. parte Escola Nacional de Agronomia. Serie didactica $\mathrm{N}^{\circ} 8.420 \mathrm{pp}$.

FAO / WORLD BANK COOPERATIVE PROGRAMME. 1983. Report of Chanchamayo - Satipo Rural Development Project. Report No 28-83. 37 pp.

Faura C. 1967. Breve reseña del estudio y prácticas entomológicas realizadas en Chachamayo y sus principales cultivos. Ponencia presentada a la XII Convención Nacional de Entomología. Tarma. Mimeografiada por la Sociedad Entomológica del Perú. $32 \mathrm{pp}$.

Figueroa R., Wolf R., Fraciosi R. \& Van O. 1970. El cultivo de la piña en el Perú. Boletín Técnico $N^{0} 75$. Lima 35 pp.

Fonseca J. P. 1973. A lagarta do abacaxi. O Biologicó, Sào Paulo. 3(1): 21-22.

González-Hernández H., Johnson M.W. \& Reimer N.J. 1999. Impact of Pheidole megacephala (F.) (Hymenoptera: Formicidae) on the Biological Control of Dysmicoccus brevipes (Cockerell) (Homoptera: Pseudococcidae). Biological Control 15: 145-152.
González-Hernández H., Pandey R.R. \& Johnson M.W. 2005. Biological characteristics of adult Anagyrus ananatis Gahan (Hymenoptera: Encyrtidae), a parasitoid of Dysmicoccus brevipes (Cockerell) (Hemiptera: Pseudococcidae) Biological Control 35: 93-103.

Harris W. V. 1927. On a Lycaenidae butterfly attacking pineapple in Trinidad. Bull. Ento. Res. 15(2): 183 -188.

Hepton A. \& Anderson E.J. 1968. Interfruitlet corking of pineapple fruti, a new disease in Hawai. Phytopathology. 58: 74-78.

Julca A. \& Bello S. 2005. Control Químico de la "mancha del fruto" en piña (Ananas comosus L. Merr.) cv. Cayena Lisa en Chanchamayo Perú. Rev. IDESIA (Chile), 23 (2): 33-38.

Julca A. \& Bello S. 1994. La "broca de la piña” Thecla basilides Gey. en la selva central del Perú. Rev. per. Ent. 36: 61-62.

Korytkowski C. 1993. Curso Internacional de Capacitación en Taxonomía de Moscas de la Fruta. Texto Básico. UNALM - IICA. Lima Perú. 135 pp.

Lara F.M., Boiça Júnior A.L. \& Tanzini M.R. 2015 CEINFO Centro de Informcões Tecnológicas e Comerciaris para Fruticultura. Última actualización 24/04/2015. Sistemas de Produção. Abacaxi - Pragas Pragas do Abacaxizeiro. http://www.ceinfo.cnpat.embrapa.br/index2.php

Le Grice D.S. \& Marr G. S. 1970. Fruit diseases control in pineapple. Faming in South Africa. 46(1): 9, 12, 17.

Menezes E.B. 1973. Bioecologia e controle de cochonilha farinhosa do abacaxi, Dysmicoccus brevipes (Cockerell, 1893) Ferris, 1950. Piracicaba: ESALQ-USP, Dissertação Mestrado. 69 pp.

MINAGRI. 2013. Ministerio de Agricultura. Boletín informativo publicado el 10 de setiembre del 2013. http://www.minag.gob.pe/portal/notas-de-prensa/notasde-prensa-2013/9535-en-los-primeros-siete-meses.

Montilla R., Lacruz L. \& Durán D. 2008. Distribución geográfica de Melanoloma viatrix Hendel (Diptera: Richardiidae) en Trujillo, Venezuela. Agronomía Trop. 58(4):403-407.

Montilla R., García J.L., Lacruz L. \& Durán L. 2007. Spalangia drosophilae Ashmead (Humenoptera: Pteromlidae) parasitoide de las pupas de la mosca de la piña Melanoloma viatrix Hendel (Diptera: Richardiidae) en Trujillo, Venezuela. Agronomia Trop. 57(2): 107 112.

Muorichon X. 1982. Contribution à l'etude de la maladie des taches noirs de l'ananas en Côte - d'Ivoire. Réunion Annuelle IRFA, doc interne, $\mathrm{N}^{\circ} 14$.

Petty G. J. 1978. Pineapple mites. Farming in South Africa, Pineaple Series H. 15.

Py C., Lacoeuilhe J.J. \& Teisson C. 1987. The pineapple cultivation and uses. Ed. G. P. Maisonneuve et Larose. Paris 568 Pág.

Py C., Lacouilhe, J.J. \& Teisson C. 1984. L' Ananas sa culture ses produits. Édittions G. - P. Maisonnueve \& La Rose. Paris. 562 pp.

Qin Z.Q., Wu J., Qiu Bao-li, Ren S. \& Ali S. 2011. Effects of host plant on the development, urvivorship and reproduction of Dysmicoccus neobrevipes Beardsley (Hemiptera: Pseudoccocidae). Crop Protection, 30(2011): 1124e1128.

Robbins R.K. 2010. The "upside down" systematics of hairstreak butterflies (Lycaenidae) that eat pineapple and 
other Bromeliaceae. Studies on Neotropical Fauna and Environment. 45(1): 21-37.

Robbins R.K. Anderson R.A \& Bolling J. 2012. The Nicaraguan hairstreak butterfly fauna (Theclinae: Eumaeini), its biogeography, and the history of Nicaraguan collectors. Journal of the Lepidopterists' Society 66(2): 61-75.

Robbins R.K. \& Nicolay. S.S. 2002. An overview of Strymon Hübner (Lycaenidae, Theclinae, Eumaeini). Journal of the Lepidopterists' Society 55: 85-100.

Rohrbach, K.G. \& Pfeiffer J. 1976a. Field induction of pineapple interfruitlet corking, leathery pocket an fruitlet core rot with Penicillium foniculosum. Phytopatology 66(4): $392-395$.

Rohrbach, K. G. \& Pfeiffer J. 1976b. The interaction of four bacteria causing pink disease of pineapple with several pineapple cultivars. Phytopatology 66(4): 396 - 399.

Santa Cecília L.V.C. \& Reis P.R. 1985. A cochonilha e a murcha do abacaxizeiro. Informe Agropecuário, 130(11): 37-41.

Santa Cecília L.V.C. \& Rossi M.M. 1991. Eficiência comparativa de alguns inseticidas e métodos de aplicação no controle da cocho-nilha-do- abacaxi. Pesquisa Agropecuária Brasileira, Brasília, 26(6): 843-848.

Sether D.M., Ullman D.E. \& Hu J.S. 1998. La transmisión del virus del bronceado asociada a la cochinilla piña por dos especies de cochinilla (Dysmicoccus spp.). Fitopatología, 88 (11): 1224-30.

Schmid S., Schmid VS., Kamke R., Steiner J. \& Zillikens A. 2010. Association of three species of Strymon Hübner (Lycaenidae: Theclinae: Eumaeini) with bromeliads in southern Brazil. Journal of Research on the Lepidoptera. 42: 50-55.

Velazco H., Ibarra G., Ceballos E. \& Sifuentes J. 1968. Biología y control del gusano barrenador Techla sp. de la piña en el sureste de México. Agricultura Técnica $\mathrm{N}^{\circ}$ 2:426-429.

Villalobos A. \& Luque JE. 2012. Aspectos biológicos de Melanoloma viatrix Hendel 1911 (Diptera: Richardiidae) en condiciones de laboratorio. Revista Agricultura Tropical 35(5 y 6): 52-67.

Villalobos A., Aguadelo JC., Barajas AF., Herrea S. \& Céspedes JC. 2009. Cambios morfológicos durante la ontogenia del estado pupal de Melanoloma viatrix (Diptera: Richardiidae). Revista Colombiana de Entomología 35(1):98-100.

\footnotetext{
${ }^{1}$ Docente investigador, Laboratorio Ecología de Artrópodos, Departamento de Biología Universidad Nacional Agraria La Molina, Av. La Universidad S/N, Lima- Perú. acg@lamolina.edu.pe.

${ }^{2}$ Docente, investigador y Jefe del Museo de Entomología “Klaus Raven Büller”, Universidad Nacional Agraria La Molina, Av. La Universidad S/N, La Molina Lima - Perú Correo electrónico cvc@lamolina.edu.pe.

${ }^{3}$ Ing. Agrónomo Grupo Frutas Golden - San Ramón-Chanchamayo. sbello@frutasgolden.com.
} 